\title{
KENYAMANAN RUANG PERPUSTAKAAN DENGAN PRINSIP GREEN OFFICE
}

\author{
Oleh: \\ Endang Fatmawati \\ Universitas Diponegoro, Semarang
}

\begin{abstract}
The concept of an environmentally friendly library office can cut operating costs. The impact of excessive energy consumption is one of the factors behind the need to conceptualize library space with the green office principle. Librarians as the main actors who manage the library, must be trained and have the competence to realize the green office. In the context of college library space, the green office can be explained as a concept for managing an environmentally friendly work environment and reducing the adverse effects of space building on the campus environment. The management in question includes: designing, building, and maintaining rooms to increase productivity for the inhabitants of the library. The library office is designed to collaborate with the surrounding environment whose activities are carried out with environmentally friendly principles. The goal is that the work environment in the library will be a comfortable, conducive, clean, shady, beautiful and healthy place for the knowledge-takers who are in it. Some programs that can be done include representative buildings, flexible space design, energy efficiency, power management features; saving water; resources efficiency; green information technology; physical design; waste management; air quality; minimize noise; space design; air freshener; or utilizing scrap paper.
\end{abstract}

Keywords: environmentally friendly, green office, energy saving, library, convenience

\section{Pendahuluan}

Energi menjadi faktor krusial bagi keberlangsungan sebuah negara. Eksistensi sebuah negara menjadi kuat dengan terpenuhinya kebutuhan energi yang seimbang antara pasokan dan kebutuhan (supply and demand), jaminan keamanan (security), maupun keberlanjutan (sustainability). Secara umum Indonesia memiliki banyak potensi untuk meningkatkan efisiensi penggunaan energi, seperti halnya dalam konteks ini menyangkut salah satu sektor dari bangunan perpustakaan.

Green Building Council Indonesia (GBCI) yang merupakan lembaga mandiri (nongovernment) yang berkomitmen penuh terhadap pendidikan masyarakat dalam mengaplikasikan praktik terbaik lingkungan dan memfasilitasi industri bangunan global yang berkelanjutan, menyebutkan 6 (enam) aspek evaluasi green building, yaitu: tepat guna lahan, efisiensi \& konservasi energi, konservasi air, sumber \& siklus material, kualitas udara \& kenyamanan ruang, serta manajemen lingkungan bangunan. Perpustakaan menjadi tempat utama bagi pemustaka dalam mencari sumber informasi, sehingga faktor kenyamanan ruang perpustakaan menjadi aspek yang fundamental. Motivasi instrinsik pustakawan menjadi dominan dalam menstimulus produktivitas kerja, disamping juga lingkungan kerjanya. Banyak kita jumpai hal-hal yang sebetulnya sangat tidak efisien dan ada indikasi tidak disiplin. Misalnya kebanyakan PC di kantor dibiarkan tetap menyala meskipun tidak digunakan, sehingga kondisi ini dapat menyebabkan pemborosan listrik, konsumsi listrik meningkat yang menyebabkan pengeluaran biaya listrik juga membengkak. Belum lagi persoalan penggunaan air, lampu, AC, dan yang lainnya.

Issue dan kondisi terkini menyangkut kenyamanan ruang perpustakaan dalam 
perspektif green office sangat menarik untuk dibahas. Dari uraian singkat pada persoalan yang dikemukakan, tulisan pendek ini akan mencoba memberikan uraian deskriptif analitis tentang signifikansi dan relevansi peran pustakawan dalam upaya mewujudkan kenyamanan ruang perpustakaan dengan prinsip green office.

\section{Pembahasan}

\section{Konsep Dasar Energi}

Energi dikonsepkan sebagai daya atau tenaga yang dapat dimanfaatkan untuk melakukan berbagai kegiatan yang berhubungan dengan listrik, mekanik, dan panas. Kesadaran untuk menghemat sumber daya alam akibat menipisnya sumber energi tak terbarukan menjadi aspek krusial. Energi bisa dalam kategori terbarukan (misalnya: tenaga surya, tenaga air, tenaga angin, geothermal) maupun energi yang tak terbarukan yang keberadaannya akan habis seiring dengan waktu (misalnya: batubara, bahan bakar nukir, minyak mentah). Harus disadari bahwa sumber daya lingkungan (udara, air, lahan, biota) itu dapat menyediakan barang dan jasa untuk mendapatkan nilai ekonomis. Dalam Usman (2010: 5) dijelaskan bahwa energi disediakan dan didayagunakan untuk memenuhi kebutuhan rumah tangga (residential), mendukung kegiatan bisnis dan industri (industrial), dan sebagai barang yang diperdagangkan (commercial).

Indonesia dikenal sebagai sebuah negara dengan kekayaan sumber daya alam dan sumber daya energi yang melimpah ruah. Persoalan energi gobal di Indonesia disamping dipengaruhi oleh faktor ketergantungan yang besar terhadap sumber daya energi konvensional (fosil), namun juga karena faktor peningkatan kebutuhan energi sebagai dampak dari peningkatan jumlah penduduk dan tuntutan standar hidup yang lebih baik. Krisis energi akibat pemakaian yang terus meningkat bisa saja terjadi, begitu juga terjadinya fenomena pemanasan global yang mengakibatkan perubahan iklim. Ironis jika kita misalnya mendengar penebangan hutan secara besar-besaran (deforestasi), penambangan liar, dan aktivitas destruktif lainnya. Hal ini karena kurang kepedulian terhadap lingkungan dalam segala aspek kehidupannya. Oleh karena itu, teknologi yang mampu menghasilkan energi bersih dan yang ramah lingkungan menjadi priorotas utama. Sebagaimana yang diamanatkan konstitusi, kita semua tahu bahwa Indonesia dituntut untuk melakukan pembangunan di segala bidang untuk mencapai kesejahteraan rakyat.

Pada dasarnya pembangunan adalah untuk meningkatkan kesejahteraan masyarakat. Pola dan cara-cara membangun maupun kegiatan pemanfaatan sumber daya alam akan menentukan besaran dampak yang ditimbulkan pada lingkungan hidup. Terkait dengan kata green office muncul pula istilah green yang lainnya, seperti green economy dan green technology. Pengembangan ekonomi hijau (green economy) mengupayakan peningkatan kesejahteraan dan keadilan sosial untuk mengurangi kelangkaan sumber daya alam dan resiko dampak lingkungan, sedangkan green technology yaitu teknologi yang diaplikasikan untuk meminimalkan dampak lingkungan. Hatta dalam Djajadiningrat, Hendriani, Famiola (2011: iii) menegaskan bahwa ekonomi hijau adalah suatu keniscayaan. Ekonomi hijau menjadi paradigma pembangunan yang didasarkan pada efisiensi pemanfaatan sumber daya (resources efficiency), pola konsumsi dan produksi yang berkelanjutan (sustainable consumption and production pattern), maupun internalisasi biaya-biaya lingkungan dan sosial (internalization the externalities). Begitu juga dengan konsep green science yang kita dengar. Martha Tilaar dalam kata pengantarnya (2011) menyampaikan bahwa konsep "live with nature" sudah menjadi falsafah hidup bangsa Indonesia 
sejak dulu. Jadi tren dunia yang mengangkat green science sebenarnya sudah merupakan hal yang sehari-hari dilakukan oleh masyarakat Indonesia.

Pengaruh ruang perpustakaan terhadap perilaku manusia sangat erat kaitannya, sehingga ruang yang didesain dengan prinsip green office diharapkan mempunyai bentuk, perabot, dan kondisi ruang yang representatif dan akomodatif. Dalam praktiknya, manusia dan lingkungan sekitarnya terus berinteraksi satu sama lain. Lingkungan dipengaruhi oleh sejumlah aspek, dan pada saat yang sama konsekuensi dari dampak lingkungan juga mempengaruhi beragam aspek. Figueiredo and Guillen (2012: 9) menyebutkan aspeknya seperti: preferences, choices, dan decision in daily life.

Dalam praktiknya bahwa tidak selamanya program hemat energi itu berpengaruh pada kenyamanan sebuah ruang. Contohnya bangunan ruang perpustakaan yang dirancang dengan menggunakan dinding kaca sebagai pencahayaan alami. Jika dianalisis hal ini memang hemat energi listrik, namun demikian menyebabkan kondisi ruang menjadi panas, sehingga di sisi lain berarti tidak memenuhi tingkat kenyamanan sebuah ruangan. Oleh karena berbasis deskriptif analitis maka tulisan ini berorientasi pada pemecahan masalah. Pustakawan harus paham terhadap kondisi ruang dan bangunan perpustakaan yang ada sehingga mampu memberikan solusi pemecahan masalah yang riil terjadi di lapangan.

\section{Kenyamanan Ruang}

Kenyamanan dalam ruang (indoor comfort) menjadi dambaan bagi sumber daya manusia yang menempati ruang. Lingkungan kerja yang nyaman sangat dibutuhkan oleh seluruh penghuni ruang agar mereka dapat bekerja secara optimal. Kualitas lingkungan dalam ruangan (indoor environmental quality) menjadi suatu hal yang sangat penting. Barnes (2012: 400) menjelaskan bahwa selama fase desain, maka perlu menentukan bahan dan barang seperti perekat, cat, karpet/ubin, kayu, maupun furnitur yang akan digunakan.

Lingkungan kerja di perpustakaan harus dikelola dengan profesional dengan desain yang green office agar suasana kantor menjadi kondusif dan nyaman untuk melaksanakan kegiatan mereka. Hal ini diupayakan dengan memprioritaskan yang lebih baik untuk lingkungan sehingga membuat ruang perpustakaan menjadi lebih sehat untuk ditempati baik pustakawan maupun pemustakanya. Seperti halnya dengan penerapan program ramah lingkungan di beberapa kampus di Indonesia yang biasa dikenal dengan nama kampus hijau (green campus) juga mensyaratkan adanya parameter tertentu.

Komponen pokok dari kampus hijau ini salah satunya adalah adanya program bangunan hijau (green building). Penghuni ruang perpustakaan harus senantisa memperhatikan faktor-faktor dalam suatu lingkungan kerja, seperti: temperatur/suhu, kelembaban udara, intensitas pencahayaan, tingkat kebisingan, dan tidak kalah penting adalah beban kerja pustakawannya. Hal ini sangat penting, karena bagaimanapun kesesuaian faktor tersebut akan berimplikasi pada produktivitas kerja bagi para penghuninya. Begitu juga jika terlalu dingin, terlalu bising, terlalu pengap, dan faktor lainnya yang tidak standar.

Misalnya AC kantor seharian mati sementara beban kerja dikejar dead line. Bisa dibayangkan kondisi bekerja di lingkungan kerja yang panas ditambah dengan beban kerja yang berat, maka hal ini jelas sangat berbahaya bagi kesehatan dan juga menurunkan tingkat konsentrasi. Jika dipaksakan maka bisa jadi hasil kerjanya tidak maksimal. Ibaratnya semakin tinggi temperatur udara maka semakin tinggi juga pengaruh kelembaban udara terhadap tubuh manusia. 
Selanjutnya semakin tinggi tingkat beban kerja maka semakin besar pengaruh kelembaban dan temperatur udara tersebut terhadap perubahan laju detak jantung yang berpengaruh pada produktivitas kerja-nya. Suwardi dan Daryanto (2018: 189) menyampaikan bahwa untuk meningkat-kan kesejateraan harus dilakukan melalui pekerjaan yang diselaraskan dengan lingkungan yang aman, nyaman dan higienis sehingga kesehatan, keselamatan dan produktivitas tenaga kerja senantiasa dapat terjamin.

Ketika terjadi fenomena kerusakan lingkungan pada bangunan perpustakaan dan sekitarnya, biasanya kita baru sadar perlunya menjaga kelestarian lingkungan tersebut. Ruang perpustakaan perlu dilengkapi dengan alat untuk memadamkan api secara otomatis jika terjadi kebakaran (splinker), menggunakan tipe AC dengan sensor yang suhunya bisa menyesuaikan secara otomatis (ceiling cassete), alat untuk mendeteksi asap rokok di ruangan ber-AC (smoke detector), dan lain sebagainya.

Bagaimanapun faktor lingkungan kantor juga menjadi pemantik produktivitas kerja pustakawan. Salah satu upaya yang tidak bisa ditawar untuk turut menjaga kelestarian lingkungan yang bisa dilakukan oleh para praktisi perkantoran adalah menerapkan konsep ramah lingkungan dalam kegiatan perkantoran. Hal ini bisa faktor fisik dan faktor sosial. Untuk faktor fisik menyangkut dimensi tempat, suasana ruang, warna, susunan perabot. Sementara itu, faktor sosial seperti norma, kultur, adat istiadat. Dalam konteks green office lebih pada aspek fisik yang dominan berpengaruh.

\section{Contoh: Aspek Pencahayaan}

Implementai perpustakaan berkonsep ramah lingkungan memiliki beberapa dimensi yang perlu direncanakan dan dipertimbangkan. Dalam Sugiarto dan Dewi (2016: 53) disebutkan misalnya: sistem pencahayaan, teknologi perkantoran, tata ruang, pengaturan udara, pemanfaatan bahan atau material kantor, pemanfaatan air, pengelolaan limbah atau sampah di kantor, serta konservasi energi di kantor.

Bangunan perpustakaan yang bertingkat menyebabkan konsumsi energi sangat besar, terutama untuk lampu dan AC. Untuk penerangan ruang, perpustakaan dapat menerapkan sistem pencahayaan yang sekiranya jauh lebih efisien dan hemat energi. Hal ini seperti: pengalihan dengan lampu hemat energi, penggunaan alat sensor yang bisa otomatis mengatur nyala lampu berdasarkan aktivitas pergerakan orang di ruangan (motion sensor switch), sistem panel surya (solar panel system), maupun cahaya alami dari sinar matahari.

Salah satu dimensi yang terkait dengan aspek pencahayaan, bahwa pencahayaan pada ruang perpustakaan yang alami berbeda dengan pencahayaan buatan. Pencahayaan alami (daylighting) adalah pencahayaan yang berasal dari matahari, yang masuk dan terkontrol ke dalam gedung, baik secara langsung ataupun menyebar (diffuse) melalui lubang cahaya (jendela, skeylight, dsb). Dalam pemanfaatan cahaya alami, masuknya radiasi matahari langsung ke dalam bangunan harus dibuat seminimal mungkin. Hal ini sangat efektif untuk meminimalisasi pemakaian energi listrik dan memperpanjang usia lampu. Tingkat pencahayaan alami dalam ruang ditentukan oleh intensitas cahaya matahari pada bidang datar di ruang terbuka pada saat yang sama.

Sistem pencahayaan alami pada ruang perpustakaan harus didesain agar bangunan dapat seoptimal mungkin memasukkan sinar matahari untuk digunakan sebagai sumber cahaya pada siang hari. Pencahayaan alami dikatakan baik apabila pada siang hari terdapat cukup banyak cahaya yang masuk ke dalam ruangan, kemudian distribusi 
cahaya di dalam ruangan cukup merata, serta tidak menimbulkan kontras yang mengganggu. Terkait dengan pencahayaan alami ini, Li Wang (2009) menegaskan bahwa dari segi arsitektur, maka gedung dapat dirombak agar lebih efisien misalnya dalam pemanfaatan cahaya alami. Penempatan dinding yang strategis, langit-langit yang ditinggikan serta jendela yang diperbanyak dapat membantu mengoptimalkan cahaya alami di dalam ruangan, sehingga dapat mengurangi pemakaian energi listrik pada lampu sampai dengan 20\%.

Perbandingan tingkat pencahayaan alami di dalam ruangan dengan di ruang terbuka ditentukan oleh: hubungan geometris antara titik ukur dan lubang cahaya, ukuran dan posisi lubang terang langit, distribusi terang langit, maupun bagian langit yang dapat dilihat dari titik ukur. Perlu diketahui bahwa matahari sebagai sumber cahaya alami terbesar memiliki spektrum cahaya yang lebar, mulai yang berfrekuensi rendah (gelombang radio) hingga yang berfrekuensi tinggi (sinar kosmis). Seberapa kuatnya cahaya yang dipancarkan sumber cahaya (intensitas cahaya) ke arah bangunan perpustakaan sangat berperan dalam proses penciptaan ruang untuk aktivitas.

Pencahayaan buatan (artificial light) merupakan segala bentuk cahaya yang bersumber dari peralatan ciptaan manusia, misalnya: lampu, lilin, obor. Pencahayaan buatan ini bukanlah sekedar menyediakan cahaya dan intensitasnya saja, namun juga untuk menciptakan kesan dan suasana. Pencahayaan buatan diperlukan apabila posisi ruangan sulit dicapai oleh pencahayaan alami tidak mencukupi untuk menerangi sebuah ruangan.

Terkait dengan pencahayaan, dalam SNI 03-6197-2000 tentang "Konservasi energi pada sistem pencahayaan" memuat ketentuan pedoman pencahayaan pada bangunan gedung untuk memperoleh sistem pencahayaan dengan pengoperasian yang optimal sehingga penggunaan energi dapat efisien tanpa harus mengurangi dan atau mengubah fungsi bangunan, kenyamanan dan produktivitas kerja penghuni serta mempertimbangkan aspek biaya. Daya pencahayaan untuk perpustakaan tidak boleh melebihi standar yang telah ditetapkan dalam SNI tersebut. Untuk menghitungnya maka perlu mengetahui jumlah dan spesifikasi daya lampu yang digunakan pada area yang akan dianalisis. Beberapa contoh SNI yang terkait dengan bangunan gedung, misalnya:

a. SNI 03-2396-2001 Tata Cara

Perancangan Sistem Pencahayaan Alami pada Bangunan Gedung;

b. SNI 03-6190-2000 Konservasi Energi Sistem Tata Udara pada Bangunan Gedung;

c. SNI 03-6389-2000 Konservasi Energi Selubung Bangunan pada Bangunan Gedung;

d. SNI 03-6196-2000 Prosedur Audit Energi pada Bangunan Gedung;

e. SNI 03-6572-2001 Tata Cara Perancangan Sistem Ventilasi dan Pengkondisian Udara pada Bangunan Gedung;

f. SNI 03-6575-2001 Tata Cara Perancangan Sistem Pencahayaan Buatan pada Bangunan Gedung;

g. SNI 16-7062-2004 Pengukuran Intensitas Penerangan di Tempat Kerja.

Selanjutnya untuk daya pencahayaan maksimum, tingkat pencahayaan rata-rata, renderasi, dan temperatur warna untuk perpustakaan, dapat dilihat seperti pada Tabel berikut:

\begin{tabular}{|cl|l|}
\hline \multicolumn{1}{|c|}{ Uraian } & \multicolumn{1}{c|}{ Standar } \\
\hline 1. & $\begin{array}{l}\text { Daya } \\
\text { Pencahayaan } \\
\text { Maksimum } \\
\left(\text { Watt } / \mathrm{m}^{2}\right)\end{array}$ & \\
\hline 2. & $\begin{array}{l}\text { Tingkat } \\
\text { Pencahayaan } \\
\text { (Lux) }\end{array}$ & 300 lux \\
\hline 3. & Kelompok \\
& Renderasi Warna & $\begin{array}{l}1: \mathrm{Ra} \text { indeks } 81- \\
100 \% \text { atau } \\
\text { 2: Ra indeks } 61-80 \%\end{array}$ \\
\hline
\end{tabular}




\begin{tabular}{|c|c|}
\hline Uraian & Standar \\
\hline $\begin{array}{ll}\text { 4. } & \text { Temperatur } \\
\text { Warna (Kelvin) }\end{array}$ & $\begin{array}{l}\text { Cool white: } 3300 \mathrm{~K} \\
-5300 \mathrm{~K} \\
\text { Daylight: }>5300 \mathrm{~K}\end{array}$ \\
\hline
\end{tabular}

Sumber: disarikan dari SNI 03-6197-2000.

Pencahayaan dapat mempengaruhi kondisi seseorang. Bagi perancang ruang, maka pencahayaan ini difungsikan untuk memenuhi kebutuhan ruang akan cahaya dan sisi estetika. Dari sisi estetika misalnya cahaya buatan untuk menonjolkan objek atau memberi efek khusus dari sudut-sudut ruang. Tingkat pencahayaan dalam suatu ruangan perpustakaan idealnya harus disesuaikan dengan fungsi dari ruangan. Misalnya ketika aktivitas yang dilakukan membutuhkan ketelitian yang tinggi maka tingkat penerangan yang dibutuhkan juga semakin besar.

Renderasi warna merupakan kemampuan sumber cahaya untuk mendefinisikan warna sebenarnya dari suatu obyek atau benda. Semakin tinggi nilai renderansi warna suatu sumber cahaya maka semakin baik pula kemampuan sumber cahaya tersebut dalam menunjukkan warna sebenarnya dari obyek. Setiawan (2010: 61) menjelaskan bahwa kualitas pencahayaan yang tidak sesuai dengan fungsi ruang berakibat pada tidak berjalannya dengan baik kegiatan yang ada. Pencahayaan yang terlalu terang akan menyebabkan silau dan kurang baik bagi mata.

Selanjutnya pilihan warna berfungsi sebagai penciptaan suasana dan nuansa pada ruangan, memberikan kesan tertentu seperti: formal, sejuk, hangat, dan mewah. Temperatur warna cahaya lampu tidak memberikan indikasi pengaruh terhadap warna obyek, tetapi lebih berpengaruh terhadap suasana ruangan. Dengan demikian, pemilihan temperatur warna lampu bergantung pada tingkat iluminansi yang diperlukan agar diperoleh pencahayaan yang sesuai dengan fungsi ruang. Warna cahaya lampu (Correlated Colour Temperature $=C C T$ ) tidak merupakan indikasi tentang efeknya terhadap warna obyek, tetapi lebih kepada memberi suasana. Pemilihan warna lampu bergantung pada tingkat iluminansi yang diperlukan agar diperoleh pencahayaan yang nyaman. Semakin tinggi tingkat iluminansi yang diperlukan maka warna lampu yang digunakan adalah jenis lampu dengan CCT sekitar $>5.000$ $\mathrm{K}$ atau warna putih, sehingga tercipta pencahayaan yang nyaman. Sebaliknya untuk kebutuhan tingkat iluminansi yang tidak terlalu tinggi, maka warna lampu yang digunakan adalah warna putih kekuning-kuningan. Menurut SNI 036197-2000 bahwa warna cahaya lampu dikelom-pokkan menjadi:

a. Warna putih kekuning-kuningan (warm-white), kelompok 1 (<3.300 K);

b. Warna puth netral (cool-white), kelompok $2(3.300 \mathrm{~K}-5.300 \mathrm{~K})$;

c. Warna putih (daylight), kelompok 3 (> $5.300 \mathrm{~K}$ )

\section{Perpustakaan Ramah Lingkungan}

Berawal dari inisiatif World Wildlife Fund (WWF) untuk mewujudkan suasana perkantoran yang ramah lingkungan di Inggris, maka lahirlah gerakan "green office" yang selanjutnya dalam perkembangannya juga diadopsi oleh negaranegara lain, termasuk Indonesia. Secara makro, energi menjadi kebutuhan mutlak bagi pemenuhan kebutuhan hidup manusia dan pembangunan negara. Salah satu terobosan dalam lingkup lebih mikro di perkantoran adalah prinsip green office ini. Hasil penelitian terdahulu yang membahas perpustakaan dengan go green dalam perspektif perilaku informasi, pernah dilakukan oleh Fourie (2012) yang hasilnya bahwa "going green" dan "paperless" dapat mengatasi masalah mulai perencanaan bangunan hijau perpustakaan hingga menilai pengalaman para Profesional LIS dalam mengembangkan "green libraries" secara berkelanjutan. Rekomendasinya adalah perlu mempertimbangkan dan melanjutkan penelitian 
tentang konsep perpustakaan hijau ke depan.

Kesadaran semua stakebolder di atmosfir perpustakaan dalam mewujukan lingkungan ramah lingkungan menjadi sangat esensial. Ruang kantor perpustakaan yang dibangun dengan konsep green library, akan menjadi sumber kekuatan tersendiri bagi pustakawannya untuk beraktivitas dan meningkatkan produktivitas kerja. Jika dikaitkan dengan konsep arsitektur hijau (green architecture), saya sepakat dengan pendapat Pradono (2008) yang menjelaskan bahwa pada dasarnya "green" mengandung prinsip berkelanjutan (sustainable), ramah lingkungan (earthfriendly), dan bangunan dengan penampilan yang sangat baik (bigh performance building).

Untuk meningkatkan kualitas layanan, ruang perpustakaan perlu didesain dengan teknologi bangunan hijau. Penelitian terkait teknologi bangunan hijau di perpustakaan umum, pernah dilakukan oleh Barnes (2012). Tujuannya untuk memberikan gambaran tentang teknologi bangunan hijau dan praktiknya, kemudian bagaimana perpustakaan umum dapat menggunakannya sebagai alat untuk mengajari komunitasnya tentang keberlanjutan dan mendorong perubahan perilaku. Temuan penelitian Barnes (2012: 397) bahwa Perpustakaan Umum Fayetteville melampaui teknik dasar, karena tidak hanya meningkatkan keberlanjutan operasi namun juga menjadi tempat uji coba komunitas pada proyek energi terbarukan (renewable). Banyak perpustakaan bersertifikasi Leadership in Energy and Environmental Design (LEED) mempublikasikan teknologi hijau yang digunakan dalam proyek pembangunan mereka. Hal ini termasuk beberapa program sponsor yang terkait dengan bangunan hijau dan yang sudah permanen di perpustakaan untuk menjelaskan bagaimana teknologi bekerja.
Konsep perpustakaan yang ramah lingkungan (green office) menjadi dambaan siapapun. Contoh perpustakaan yang menerapkan desain green library misalnya Taipei Public Library, Taiwan (Tseng, 2008). Semua upaya yang kita rencanakan dalam membuat green library tiada lain adalah sebagai salah satu bentuk kontribusi nyata dari instansi dan pustakawannya dalam upaya melestarikan lingkungan dalam lingkup perkantoran. Mengadopsi pendapat dari Wrap (2009: 3) terkait dengan manfaat dari green office, maka jika diaplikasikan ke ranah perpustakaan dapat penulis jelaskan manfaatnya, yaitu: mengurangi biaya, peningkatan efisiensi sumber daya, mengurangi jejak karbon, peningkatan kinerja lingkungan, peningkatan citra perpustakaan, serta pustakawan lebih memiliki kesadaran ramah lingkungan.

Layanan sirkulasi perpustakaan bisa memanfaatkan teknologi barcode system maupun Radio Frequency Identification (RFID) sehingga tidak boros file arsip kertas. Pembayaran denda keterlambatan dengan pembayaran nontunai menggunakan kartu elektronik dengan menggesekkan pada mesin Electronic Data Capture (EDC) sehingga lebih efisien. Penyerahan tugas akhir, skripsi, tesis, disertasi dengan soft file dalam $\mathrm{CD}$ (paperless) sehingga menghemat tempat. Statistik kunjungan pemustaka langsung terinput melalui komputer sehingga tidak perlu menulis di buku kunjungan. Selanjutnya presensi pegawai perpus-takaan tidak dengan manual namun menggunakan mesin, misalnya finger print sehingga lebih akurat.

Kenyamanan yang tinggi dari segi visual, akustik, dan termal untuk penghuni ruang sangat penting untuk mendukung efektivitas dan kreativitas pegawai perpustakaan. Beberapa program dalam green office sebetulnya perlu ditanamkan kepada para penghuni ruang perpustakaan. Upaya yang bisa dilakukan banyak sekali, misalnya dapat saya jelaskan sebagai berikut: 
a. Desain letak bangunan yang representatif. Hal ini meliputi arah bangunan terhadap sinar matahari dan memaksimalkan penggunaan taman dengan tumbuhan hijau maupun penghijauan ruangan dengan tanaman indoor. Untuk memperindah ruangan perpustakaan, maka bisa didesain dengan memberi tanaman indoor, misalnya: di pintu masuk lift; di pojok loker tas; di meja pustakawan; di sudut ruang; selasar antar tangga naik dan turun; di toilet, dan di ruang lainnya. Ruang perpustakaan akan tampak asri dan indah jika dilengkapi dengan tanaman indoor. Tanaman hias berfungsi untuk mempercantik ruangan, menyegarkan ruangan, mengurangi debu di ruangan, mengurangi stres, mencegah ngantuk, menyehatkan mata, serta sangat bermanfaat bagi lingkungan sekitar. Banyak sekali jenis tanaman hias yang bisa dipilih untuk diletakkan di dalam ruangan perpustakaan. Berikut saya contohkan 3 (tiga) jenis. Pertama, sejenis pedang-pedangan atau lebih sering dikenal dengan istilah tanaman lidah mertua (sansevieria trifasciata laurentii). Tanaman ini berdaun tegak menjulang dengan tekstur keras dan berbentuk lidah, yang berfungsi sebagai penyerap racun atau zat berbahaya yang barangkali berasal dari cat perabot, cat tembok, pengharum ruangan, pembasmi serangga, maupun pembersih lantai. Selain itu, juga mampu menyerap berbagai jenis polutan, partikel atau debu halus di udara yang ada dalam ruangan sehingga ruang akan terasa lebih sejuk. Kedua, tanaman krisan (chrysanthemum) juga bagus untuk pembersih udara, karena tanaman krisan bisa menyerap bahan kimia atau polutan berbahaya dari udara, seperti: kandungan racun yang biasa ada pada bensin (benzena), amonia, xylene, maupun formaldebyde/ formalin. Banyak jenis dari bunga krisan, warna-warni bunganya sangat ceria, indah, dan baunya semerbak. Ketiga, genus tanaman daun hias sri rejeki (aglaonema, chinese evergreen) yang corak daunnya sangat indah dengan batang daun yang tumbuh tegak dengan daun lebar dengan corak hijau menyebar. Seperti halnya krisan, aglaonema juga berfungsi untuk membersihkan benzena dan formaldehida yang membaur dalam udara di ruangan.

b. Desain ruang yang fleksibel. Oleh karena desain ruang perpustakaan dapat mempengaruhi perilaku yang menempati, maka ruang dapat dirancang untuk memenuhi suatu fungsi yang lebih fleksibel dalam segala aktivitas dan untuk tujuan tertentu. Ruang perpustakaan yang nyaman dan asri dengan desain yang modern dapat digunakan untuk acara bedah buku, seminar, diskusi civitas akademik dan kegiatan konstruktif yang lainnya dalam upaya membumikan perpustakaan.

c. Efisiensi energi. Potensi penghematan energi pada gedung yang tanpa biaya, salah satunya adalah perubahan perilaku hemat energi. Hal ini meliputi segala elemen bangunan yang mengkonsumsi banyak energi, baik secara langsung maupun tidak. Misalnya: pemilihan kaca jendela, selubung bangunan, penggunaan peralatan listrik, pengkondisian udara, penggunaan $\mathrm{AC}$, maupun penggunaan perangkat komputer. Khusus untuk hemat energi komputer, maka penghuni ruang hendaknya senantiasa mencabut kabel listrik dari stop kontak saat peralatan tidak lagi digunakan, kemudian juga membiasakan untuk menggunakan strip sambungan listrik dengan saklar (smart power strip) untuk seluruh peralatan elektronik.

d. Penggunaan fitur power management. Caranya fasilitas komputer di ruang perpustakaan yang disediakan untuk pemustaka untuk penelusuran, akses $e$ - 
resources, OPAC, maupun akses koleksi digital, dapat diprogram secara otomatis untuk menyimpan energi sebesar 60-70\%. Untuk contoh konkritnya seperti: mengubah setting komputer dan laptop yang disediakan di ruang perpustakaan untuk selalu berada dalam keadaan stand-by mode saat tidak digunakan, menempatkan software PC pada mode yang menggunakan konsumsi baterai terendah (shutdown, bibernation, standby), mematikan sistem atau men-setting monitor pada mode sleep jika tidak digunakan, maupun mengurangi konsumsi Personal Computer (PC).

e. Penghematan air di area gedung perpustakaan. Terobosan inovatif dan kreatif seperti halnya dengan sistem manajemen tadah hujan (rain harvesting). Artinya sebagai salah satu usaha untuk melakukan penghematan air dengan cara memanfaatkan kembali air yang masih layak untuk irigasi taman atau flushing toilet. Perlu menempel poster atau tulisan di dinding toilet, misalnya: mohon kran dimatikan setelah digunakan, mohon menggunakan tisu secukupnya, mohon menjaga lantai toilet tetap dalam kondisi kering, dan lain sebagainya;

f. Efisiensi sumber daya yang meliputi energi dan material-material pembentuknya. Penggunaan material bangunan yang ramah lingkungan sesuai dengan standar SNI dapat meningkatkan performa energi bangunan perpustakaan. Dengan demikian, dampak negatif yang timbul dari intensitas penggunaan sumber daya pada bangunan terhadap kesehatan dan lingkungan dapat dikurangi atau diminimalisir.

g. Penerapan green teknologi informasi. Hal ini berkaitan dengan perencanaan dan penggunaan infrastruktur teknologi yang bersifat sustainable. Artinya mampu melayani kebutuhan pada masa sekarang dengan memperhatikan kebutuhan pada masa yang akan datang. Green ICT tidak terlepas dari banyaknya sampah elektronik (e-waste) yang antara lain berasal dari televisi, ponsel, voucher pulsa telepon, maupun jaringan. Murugesan (2008) sebagaimana dikutip oleh Yadav and Pathak (2015: 85) mengkonsepkan 4 (empat) pendekatan holistik dari green teknologi informasi, yaitu: penggunaan TIK dengan cara mengurangi konsumsi energi (green use); menggunakan kembali TIK lama yang sudah diperbaiki (green disposal); menggunakan TIK yang ramah lingkungan dan efisiensi energi (green design); membuat komponen TIK yang tidak memberikan pengaruh negatif minimal bagi lingkungan (green manufacturing). Lebih lanjut Murugesan dan Gangadharan (2012: xxxi) mengungkapkan dalam pengantar bukunya bahwa "green IT refers to environmentally sound technologies and systems, applications and practices and encompasses three complementary IT-enabled approaches to improving environmental sustainability: (i) minimize the energy consumption and environmental impacts of computing resourceshardware, software and communication system-over their life cycle; (ii) harness the power of IT and information systems empower, and (iii) leverage IT to belp create awareness among stakeholders and promote a green agenda and green initiatives".

h. Perancangan fisik ruang perpustakaan yang menarik pustakawan dan pemustaka. Hal ini meliputi: ukuran dan bentuk, perabot dan penataannya, warna interior ruang, maupun unsur lingkungan ruang (suara, temperatur, pencahayaan). Saya yakin semua aspek fisik ruang tersebut mempunyai andil besar dalam mempengaruhi kondisi ruang dan perilaku pemakainya. Senada dengan Gou (2016: 614) dalam latar belakang tulisannya yang 
menyebutkan bahwa "Green interiors are a ramification of green building, aiming to efficiently use resources and improve occupant bealth and productivity."

i. Pengelolaan sampah dengan prinsip 3R (reduce, reuse, dan recycle) di lingkungan perpustakaan. Sistem 3R lebih menekankan kepada pengu-rangan sampah yang lebih bijak dan lebih ramah lingkungan tentunya. Dalam konteks ini lebih menekankan kepada cara pengurangan sampah yang berbasis multiguna, sehingga bisa bersinergi dan berkesinam-bungan. Hal ini meliputi sosialisasi saat pengelolaan sampah mulai dikeluarkan di perpustakaan, pemahaman dalam pengelolaan sampah, sampai pada pendampingannya kepada semua unsur yang terlibat. Jadi sangat diperlukan kesadaran pustakawan terhadap dampak yang ditimbulkan dari sampahsampah yang sertiap hari semakin menggunung di perpustakaan.

j. Kualitas udara ruang perpustakaan. Hal ini wajib hukumnya untuk dijaga dengan menghilangkan kotoran debu dan polutan, atau dengan memasukkan udara segar di dalam ruang perpustakaan dengan menambah ventilasi untuk sirkulasi udara. Selain itu, bisa menggunakan bahan pembersih ruangan yang aman dan ramah lingkungan yang intinya dapat mengurangi penyebaran polutan melalui gas dan udara yang kita hirup di dalam ruangan. Jadi saya berpendapat bahwa kualitas udara di perpustakaan harus selalu dijaga untuk kepentingan kesehatan dan kenyamanan pustakawan yang berada di dalamnya.

k. Meminimalkan kebisingan seperti bunyi yang tidak diinginkan dari kegiatan dalam tingkat dan waktu tertentu yang dapat menimbulkan gangguan kenyamanan dan kesehatan manusia. Misalnya suara foto kopi, suara printer, suara perbaikan dan penjilidan buku, dan suara lainnya yang mengganggu ketenangan pustakawan. Kantor perpustakaan perlu membuat ruangan khusus yang kedap suara untuk kegiatan tertentu. Dalam memilih lagu dan musik yang diputar di setiap ruang perpustakaan juga harus dipilihkan yang tidak mengganggu, misalnya musik klasik yang instrumennya mampu menstimulus orang untuk berpikir lebih rileks.

1. Mempertimbangkan prinsip dasar membuat desain sebuah ruang perpustakaan yang baik. Hal ini bisa saya contohkan seperti: dengan mengedepankan kesehatan dan kesejahteraan pustakawan, menyedia-kan lingkungan yang nyaman dan sehat, desain ruang perpustakaan yang dapat mengikuti perubahan, mengintegrasikan teknologi terkini dengan peralatan yang mendukung, menyedia-kan sistem bangunan yang handal dengan konstruksi bangunan yang kuat dan berkualitas, serta meningkatkan kompetensi sumber daya manusia yang tersedia di perpustakaan.

m. Menggunakan pengharum ruang otomatis untuk menjaga kondisi ruang perpustakaan yang selalu harum dan beraroma segar. Selain itu, jika memungkinkan perlu mengagendakan pengadaan exhaust fan diantara indoor dan outdoor, yang fungsi utamanya untuk menghisap udara di dalam ruang perpustakaan untuk dibuang ke luar kemudian pada saat bersamaan juga menarik udara segar dari luar ke dalam ruangan.

n. Memanfaatkan kertas bekas untuk bisa dimanfaatkan dan digunakan kembali. Biasanya di halaman kertas di sebaliknya masih ada yang kosong atau belum terpakai. Keadaan kertas yang demikian dapat dimanfaatkan kembali untuk keperluan administrasi kantor. Kertas yang masih kosong misalnya dipotong kecil-kecil kemudian ditaruh di dekat meja penelusuran atau OPAC 
untuk keperluan pemustaka ketika mencatat nomor punggung buku dari hasil penelusuran online; keperluan corat-coret; keperluan formulir foto kopi, surat keterangan bebas pinjam, membuat date due slip, mencetak draft laporan yang masih belum final, menuliskan draft usulan surat, menulis daftar kunjungan, dan lain sebagainya.

\section{Penutup}

Penerapan konsep ramah lingkungan janganlah hanya sebatas slogan saja, tetapi harus diimplemen-tasikan pada semua pemangku kepen-tingan di perpustakaan. Pustakawan mempunyai peran yang sangat penting dan dapat berkontribusi besar dalam mewujudkan green office. Inovasi berkaitan dengan teknologi informasi dan komunikasi, sementara teknologi juga didasarkan pada ilmu pengetahuan yang berkembang. Green office yang merupakan konsep pengelolaan kantor perpustakaan yang ramah lingkungan perlu men-dapatkan perhatian khusus bagi pihak manajemen perpustakaan. Faktor kenyamanan dalam ruang kerja perpus-takaan menjadi salah satu hal penting yang harus diprioritaskan.

Konsep green office dapat diimplementasikan dengan baik jika ada perencanaan dan kesiapan yang matang dari SDM perpustakaan, kemudian dilakukan dengan proses desain yang terintegrasi, baik aspek arsitektur, mekanikal, maupun komitmen tegas dalam melaksanakan dari semua penghuni ruang perpustakaan. Ibarat tiada gading yang tak pernah retak, tentu masih banyak kekurangan dalam makalah ini. Diskusi yang membangun sangat penulis harapkan demi sempurnanya makalah ini. Semoga uraian singkat deskriptif analitis tentang signifikansi dan relevansi peran pustakawan dalam upaya mewujudkan kenyamanan ruang perpustakaan dengan prinsip green office ini bisa menjadi pemantik untuk diskusi lebih lanjut.

\section{Daftar Pustaka}

Badan Standardisasi Nasional. SNI 03-61972000 Konservasi Energi Pada Sistem Pencahayaan. Jakarta: BSN.

Barnes, LL (2012) Green Buildings as Sustainability Education Tools. Library Hi Tech, 30 (3):397-407.

Djajadiningrat, ST, Hendriani, Y \& Famiola, M (2011) Ekonomi Hijau (Green Economy). Bandung: Rekayasa Sains.

Figueiredo, JN \& Guillen, MF (2012) Green Products: Perspectives on Innovation and Adoption. Boca Raton London New York: CRC Press Taylor \& Francis Group.

Fourie, I (2012) A Call For Libraries to Go Green: An Information Behaviour Perspective to Draw Interest From Twenty-first Century Librarians. Library Hi Tech 30 (3):428435.

Gou, Z (2016) Green Building for Office Interiors: Challenges and Opportunities. Facilities, 34 (11/12):614-629.

Green Building Council Indonesia. The Definition in Creating Green Offices. https://www.gbcindonesia.org/downl oad/doc.../2-eco-office [Diakses 20 Mei 2018]

\section{(2016) Greenship Existing}

Building Version 1.1 Greenship Rating Tools Untuk Gedung Terbangun Versi 1.1. https://www.gbcindonesia.org/.../160ringkasan-greenship-eb-v1-1 [Diakses 20 Mei 2018].

(2011) Ringkasan Tolok Ukur

Greenship Existing Building Version 1.0. https://www.gbcindonesia.org/.../26ringkasan-tolok-ukurgreenshi...[Diakses 20 Mei 2018].

Li Wang (2009) Energy Saving of Green Building Using Natural Daylight. IEEE

Publication.

Murugesan, S (2008) Harnessing Green IT: Principles and Practices. IT Professional, 10 (1),24-33.

Murugesan, S \& Gangadharan, GR (2012) Harnessing Green IT: Principles and Practices. https://theeye.eu/public/Books/IT\%20Various/ harnessing_green_it.pdf [Diakses 20 Mei 2018].

Pradono, B (2008) Konsep Green Arcbitecture/Arsitektur Hijau. 
http:/ /www.astudioarchitect.com/200 8/11/konsep-green-architecturearsitektur_10.html [Diakses $20 \mathrm{Mei}$ 2018].

Setiawan, B (2010) Arsitektur, Lingkungan dan Perilaku: Pengantar ke Teori, Metodologi dan Aplikasi. Yogyakarta: Gadjah Mada University Press.

Sugiarto \& Dewi, YEP (2016) Green Office: Manajemen Kantor Berkonsep Ramah Lingkungan. Yogyakarta: Gava Media.

Suwardi \& Daryanto (2018) Pedoman Praktis K3LH Keselamatan dan Kesehatan Kerja dan Lingkungan Hidup. Yogyakarta: Gava Media.

Tilaar, M, Wih, WL \& Setiadi-Ranti, A (2011) Pioneers in Green Science: Beberapa Model Penerapan Konsep Ramah Lingkungan di Indonesia. Jakarta: Dian Rakyat.

Tseng, S (2008) Green Library Design and Evaluation: The Taipei Public Library,
Taiwan. New Library World, 109 (7/8):321-336.

Usman, S (2005) Kebijakan Pengembangan Energi Terbarukan. Dalam Buku "Dari Yogyakarta Untuk Energi Indonesia: Pandangan dan Hasil Riset Pakar UGM di Bidang Energi”. Editor: Jumina, Karna Wijaya, Arief Budiman. Yogyakarta: Tim Pusat Studi Energi UGM.

Wrap (2009) Green Office: A Guide to Running a More Cost-effective and Environmentally Sustainable Office. Business Resource Efficiency Guide. http://www.wrap. org.uk/sites/files/wrap/WRAP_Green _Office_Guide.pdf [Diakses $20 \mathrm{Mei}$ 2018].

Yadav, R \& Pathak, GS (2015) Going Green: A Case Study of Information Technology (IT) Sector in India. International Journal of Applied Business and Economic Research (IJABER), 13 (1):83-92. 